
PNQM08

\title{
AVALIAÇÃO DA ATIVIDADE ANTIBACTERIANA E MODULATÓRIA DO EXTRATO METANÓLICO DA FOLHA DE Myracrodruon urundeuva Fr. All.
}

\author{
J. S. CRISTO ${ }^{1}$, P. E. A. AQUINO ${ }^{1}$, P. S. PEREIRA ${ }^{2}$, S. M. A. LIMA ${ }^{2}$, S. R. TINTINO ${ }^{1}$, C. \\ D. M. OLIVEIRA ${ }^{1}$, T. G. SILVA ${ }^{2}$, H. D. M. COUTINHO ${ }^{1}$ \\ ${ }^{1}$ Universidade Regional do Cariri, Centro de Ciências Biológicas e da Saúde, Departamento \\ de Ciências Biológicas \\ ${ }^{2}$ Universidade Federal de Pernambuco, Centro de Biociências, Departamento de \\ Antibióticos
}

E-mail para contato: sandrinearruda@gmail.com

RESUMO - O surgimento de linhagens bacterianas resistentes e os efeitos adversos provenientes dos farmacos antibacterianos fazem a necessidade de pesquisas por novos principios ativos. Myracrodruon urundeuva Fr. All. é conhecida popularmente por suas propriedades medicinais: antibióticas, cicatrizantes e anti-inflamatórias. Infecções por bactérias multirresistentes envolvem várias doenças superficiais e invasivas, inclusive oportunistas, comprometendo pacientes que estão expostos a fatores de risco. A resistência adquirida por espécies como Pseudomonas aeruginosa, Escherichia coli $e$ Staphylococcus aureus ocorre por processo de mutação gênica associada com a disseminação entre as espécies. Nesse contexto, o trabalho teve como objetivo avaliar o potencial antibacteriano e modulador do extrato metanólico das folhas de M. urundeuva Fr. All. em bactérias multirresistentes. O extrato metanólico foi testado quanto ao seu efeito antibacteriano e em combinação com amicacina e gentamicina, contra P. aeruginosa, E. coli e S. aureus pelo método de microdiluição em caldo. Foi observado que, a associação entre o antibiótico amicacina e o extrato de $M$. urundeuva apresentaram antagonismo frente $P$. aeruginosa e $S$. aureus, e sinergismo frente E. coli. Mas quando o extrato de $M$. urundeuva é associado ao antibiótico gentamicina apresenta sinergismo frente todas as linhagens testadas. Sendo assim esse trabalho apresenta relevância clínica diante dos testes com P. aeruginosa, E. coli e S. aureus, obtendo ação moduladora contra os microrganismos.

Palavras chave: Pseudomonas aeruginosa, Escherichia coli e Staphylococcus aureus

ABSTRAT - The emergence of resistant bacterial strains and the adverse effects from antibacterial drugs, increase the need for research by new active principles. Myracrodruon urundeuva Fr. All. Is popularly known for its medicinal properties: antibiotics, healing and anti-inflammatory. Multiresistant bacterial infections 
involve several superficial and invasive diseases, including opportunistic infections, compromising patients who are exposed to risk factors. The resistance acquired by species such as Pseudomonas aeruginosa, Escherichia coli and Staphylococcus aureus occurs by the process of gene mutation associated with the spread among the species. In this context, the objective was to evaluate the antibacterial and modulatory potential of the methanolic extract of the leaves of M. urundeuva Fr. All. In multiresistant bacteria. The methanolic extract was tested for its antibacterial effect and in combination with amicacin and gentamicin against $P$. aeruginosa, E. coli and $S$. aureus by broth microdilution method. It was observed that the association between the antibiotic amikacin and the $M$. urundeuva extract presents antagonism against $P$. aeruginosa and $S$. aureus, and synergism with E. coli. But when the M. urundeuva extract is associated with the antibiotic gentamicin it presents synergism in front of all tested strains. Therefore, this work presents clinical relevance in the tests with P. aeruginosa, E. coli and $S$. aureus, obtaining a modulating action against the microrganisms.

Keywords: Pseudomonas aeruginosa, Escherichia coli e Staphylococcus aureus

\section{INTRODUÇÃO}

A utilização de plantas medicinais para fins de prevenção e cura de enfermidades apresenta aplicações já comprovadas, aos quais levou ao desenvolvimento de diversos medicamentos, conhecido como fitoterápicos (VEIGA; PINTO, 2005). Os medicamentos fitoterápicos são formados por uma ampla mistura de substâncias presentes na planta, preparados seguindo critérios rigorosos que obedecem à legislação da ANVISA (Agência Nacional de Vigilância Sanitária) (DI STASI, 2007). Geralmente, as combinações fitoterápicas podem ser usadas em diversas formulações como cápsula, comprimidos, géis, pomadas, soluções aquosas, soluções hidroalcoólicas e infusões, estas duas últimas são conhecidas popularmente por chás (FRANCISCO, 2010). Portanto a busca de novas plantas medicinais é uma alternativa promissora.

Myracrodruon urundeuva Fr. All. é uma espécie pertencente à família Anacardiaceae, conhecida popularmente como, urundeuva, aroeira, aroeira do sertão, aroeira do campo, aroeira da serra urindeúva e arindeúva. Apresenta ampla distribuição geográfica, podendo ser encontrada no México, Argentina, Bolívia e Paraguai. No Brasil, essa espécie ocorre principalmente na região Nordeste, Sudeste e Centro-Oeste (GUEDES et al., 2012; LORENZI, 2002). Devido às excelentes propriedades biológicas como, anti-inflamatória, cicatrizante, antiulcerogênica, anti-histamínica, antibradicinina e analgésica, M. urundeuva é muito explorada, tornando-se escassa, sendo encontrada na lista do IBMA (Instituto Brasileiro do Meio Ambiente e dos Recursos Naturais Renováveis) das espécies brasileiras ameaçadas de extinção (GUEDES et al., 2012).

A busca por novas substâncias que possuam atividade antimicrobiana sobre determinado microrganismo, vem recebendo atenção especial da comunidade cientifica. Estudos são realizados a fim de encontrar novos fármacos provenientes de plantas medicinais que exerçam ação antimicrobiana, principalmente contra microrganismos multirresistentes ou isolados clínicos (OLIVEIRA et al., 2006).

Pseudomonas aeruginosa, bactéria Gram-negativa, é um patógeno hospitalar frequente, do tipo oportunista que se manifesta em qualquer órgão do corpo humano, 
principalmente em pacientes imunocomprometidos resultando numa infecção generalizada, capaz de persistir por muitos períodos em ambientes variados e desencadear resistência a agentes antimicrobianos (GALES et al., 2001). Outro exemplo de bactéria Gram-negativa é Escherichia coli que pertencente à flora normal do intestino humano podendo contaminar e causar infecções extra intestinais, sendo um dos principais agentes etiológicos de infecção do trato urinário. Esse microrganismo é um dos agentes que apresenta alta capacidade para ampliar resistência, principalmente o sorotipo E. coli (ETEC), principal agente etiológico da diarréia neonatal (KAZMIRCZAK et al., 2005). As bactérias Gram-positivas, dentre elas espécies de Staphylococcus, são consideradas da flora normal da pele. Staphylococcus aureus é a espécie mais prevalente em surtos de infecção alimentar (SILVA et al., 2004).

Diante do exposto, esse estudo teve como propósito avaliar, in vitro, a atividade antibacteriana das folhas de $M$. urundeuva Fr. All. na inibição do crescimento de $P$. aeruginosa, E. coli e $S$. aureus.

\section{MATERIAIS E MÉTODOS}

\subsection{Material Vegetal}

As folhas de M. urundeuva Fr. All. foram coletadas no Juazeiro do Norte, Ceará, Brasil, em um sítio na serra conhecido como Caras do Mari. O material vegetal foi identificado e uma exsicata foi depositada no herbário RB (A.C. de João Marcelo A. Braga), sob número de identificação ${ }^{\circ}$ RB 592409.

\subsection{Preparação do Extrato Metanólico}

Para preparação do extrato metanólico de $M$. urundeuva forma coletada folhas, e após a coleta foram submersas em metanol por $72 \mathrm{~h}$. Após esse período, o efluente foi filtrado e concentrado em condensador rotativo a vácuo e banho Maria (BRASILEIRO et al., 2006), obtendo assim o extrato metanólico bruto. Para os ensaios microbiológicos foi pesado de $10 \mathrm{mg}$ do extrato e dissolvido em $1 \mathrm{~mL}$ dimetilsulfóxido (DMSO 99,9\%) ficando uma solução de $10 \mathrm{mg} / \mathrm{mL}$, em seguida diluídos com água destilada para uma concentração de $1024 \mu \mathrm{g} / \mathrm{mL}$.

\subsection{Microrganismos}

Os microrganismos utilizados nos testes foram obtidos do laboratório de microbiologia e biologia molecular da Universidade Regional do Cariri - URCA. Foram utilizadas três linhagens padrões de bactérias: $P$. aeruginosa ATCC (American Type Culture Collection) 15442, E. coli ATCC 10536 e S. aureus ATCC 25923. Para avaliar a atividade modulatória dos produtos naturais foram usados os seguintes isolados bacterianos multirresistentes: P. aeruginosa PA03; E. coli EC27 e $S$. aureus SA358. As cepas utilizadas foram mantidas em meio de cultura Heart Infusion Agar - HIA (Difco Ltda.) e antes dos testes as células foram cultivadas por 24 horas a $37^{\circ} \mathrm{C} \mathrm{em} \mathrm{meio} \mathrm{Brain}$ Heart Infusion BHI (Difco laboratories Ltda.).

\subsection{Drogas Utilizadas}

As drogas antibacterianas utilizadas nos testes da CMI e modulação foram da classe dos 
aminoglicosídeos (amicacina e gentamicina) que atuam diretamente no ribossomo bacteriano.

\subsection{Concentração Mínima Inibitória (CMI)}

O método utilizado foi microdiluição em caldo. O inóculo bacteriano foi diluído usando BHI $10 \%$ para uma concentração final de $10^{5} \mathrm{UFC} / \mathrm{mL}$. Foi distribuído $100 \mu \mathrm{L}$ dos inóculos em eppendorf e depois completado com meio de cultura BHI 10\% formando um solução de $1 \mathrm{~mL}$. Depois $100 \mu \mathrm{L}$ do conteúdo de cada eppendorf foram transferidos para cada poço de uma placa de microdiluição com 96 poços e, em seguida, submetidos a uma diluição 1:1 em série usando $100 \mu \mathrm{L}$ do extrato, variando as concentrações entre 512 a $8 \mu \mathrm{g} / \mathrm{mL}$ (JAVADPOUR et al., 1996). A placa foi incubada durante $24 \mathrm{~h}$ a $37^{\circ} \mathrm{C}$. E pós esse período, foi feito à leitura visual por adição de rezasurina, com mudança de coloração do meio. A CIM foi definida como a menor concentração do extrato capaz de inibir o crescimento do microbiano (CLSI, 2000).

\subsection{Teste de Modulação com Antibióticos}

Para verificar se o produto natural poderia alterar a ação de drogas antibacterianas contra as cepas testadas, foi usado o método proposto por Coutinho e colaboradores (2008). O extrato metanólico das folhas de $M$. urundeuva Fr. All. foi testado em concentração subinibitória $(\mathrm{CIM} / 8=128 \mu \mathrm{g} / \mathrm{mL})$. Sendo que foi preparada a solução contendo: $\mathrm{BHI}$ $10 \%$ com o inóculo de microrganismo com $10^{5} \mathrm{UFC} / \mathrm{mL}$; extrato em cada poço em eppedendorfs e completado com meio de BHI 10\%. Em seguida $100 \mu \mathrm{L}$ dessa solução forma transferidos para os poços de uma placa de 96 poços. E realizada a microdiduição (1:1) com $100 \mu \mathrm{L}$ dos antibióticos $(1024$ a $0,5 \mu \mathrm{g} / \mathrm{mL})$. Os controles utilizados foram a CIM dos antibióticos sozinhos, nas mesmas concentrações sem as substâncias associadas. As placas preenchidas foram incubadas a $37^{\circ} \mathrm{C}$ por $24 \mathrm{~h}$ e após esse período a leitura foi evidenciada pelo uso de resazurina como no teste de determinação da CIM. Todo o experimento foi realizado em triplicata

\subsection{Analise estatística}

Os resultados dos ensaios foram feitos em triplicata, e expressos como média geométrica. A análise estatística aplicada foi a two-way ANOVA seguido por pós-teste de Bonferroni com o software GraphPadPrism 5.0

\section{RESULTADOS E DISCUSSÃO}

A atividade antibacteriana do extrato metanólico da folha de $M$. urundeuva (EMMU) apresentou $\mathrm{CMI} \geq 1024 \mu \mathrm{g} / \mathrm{mL}$ frente às bactérias $P$. aeruginosa, E. coli e $S$. aureus. Não clinicamente relevante.

Quando uma substância é combinada com um antibiótico e ocorre aumento da atividade do antibiótico, geralmente pela redução do CIM, classifica esse fenômeno como efeito sinérgico. Mas quando há efeito contrário da ação do antibiótico, ou seja aumento do CIM, indica-se que aconteceu um efeito antagônico (CANTON; ONOFRE, 2010). Na associação do extrato em combinação com a amicacina frente a $P$. aeruginosa e a $S$. aureus foi observado antagonismo (aumento da concentração do antibiótico reduzindo o potencial antibacteriano, quando comparado com o efeito da amicacina isolada). Para a combinação amicacina+EMMU frente a $E$. coli e combinação 
gentamicina+EMMU para todas as linhagens bacterianas foi observado sinergismo (redução da concentração do antibiótico aumentando o potencial antibacteriano, quando comparado com o efeito da amicacina e gentamicina isolada), conforme a Figura 1.

Figura 1 - Representação do efeito modulador de Myracrodruon urundeuva.

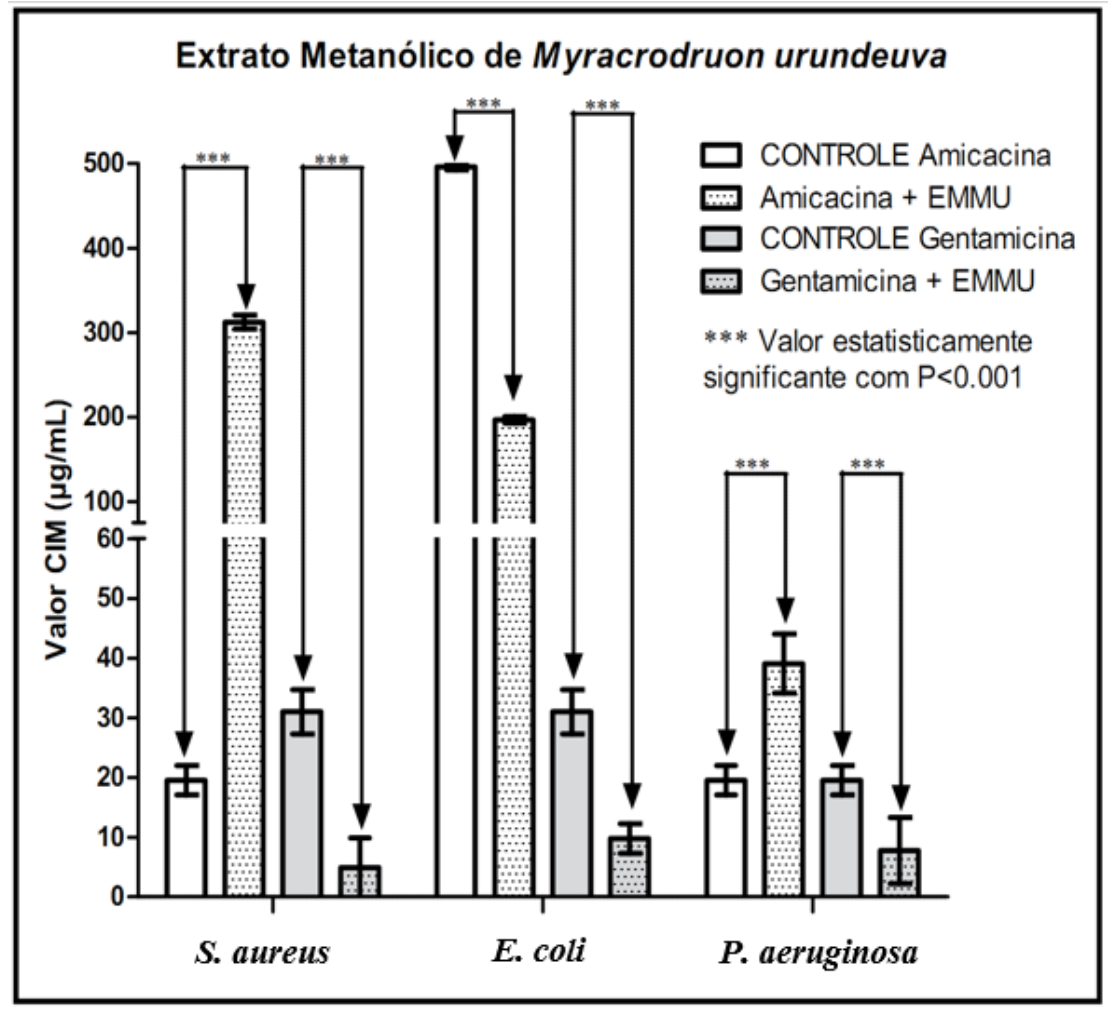

* EMMU (extrato metanólico da folha de M. urundeuva)

Varios estudos evidenciaram que extratos e óleos essenciais de plantas podem transformar a atividade dos antimicrobianos e assim reformar seu desempenho, reduzindo a concentração necessária afim de inibir o crescimento dos microrganismos (MATIAS et al, 2010).

Estudos de atividades antimicrobianas de M. urundeuva já foram descritos anteriormente por Figueredo e colaboradores (2014), que demonstraram a atividade do óleo essencial contra as cepas bacterianas patogênicas utilizando o método de modulação com antibióticos. Também pode ser vista a atividade antimicrobiana do extrato hidroalcoólico através do teste de difusão em ágar por Pinho e colaboradores (2012).

A combinação de produtos naturais com aminoglicosídeos pode ser uma das formas de diminuir os efeitos indesejáveis dos antibióticos, quando submetido ao tratamento de infecções ocasionadas por bactérias Gram-positivas ou Gram-negativas. Essa combinação pode conduzir a um efeito sinérgico permitindo, assim, utilização de doses mais baixas para o sucesso terapêutico (FIGUEREDO et al., 2014). Os produtos de origem vegetal podem modificar o efeito dos antibióticos, aumentando ou diminuindo a sua atividade, portanto sendo chamados de modificadores de atividade antibiótica (COUTINHO et al., 2008).

Vários componentes de extratos podem aumentar a permeabilidade da membrana 
celular, aumentando a penetração de antibióticos (HELANDER et al., 1998). A interferência com os sistemas enzimáticos das bactérias também pode ser um potencial mecanismo de ação (WENDAKOON; SAKAGUCHI, 1995). Estes mecanismos de ação podem ser obtidos pela combinação de antibiótico com extrato em concentração subinibitória, aplicado diretamente ao meio de cultura (COUTINHO et al., 2010). Esta estratégia refere-se à utilização de plantas e drogas em uma abordagem usando mono ou multi-combinações de extrato, que podem afetar não somente um único alvo, mas vários alvos, onde os diferentes componentes terapêuticos colaboram de uma forma sinérgica agonista.

\section{CONCLUSÃO}

O extrato metanólico da folha de $M$. urundeuva apresentou atividade antibacteriana, principalmente quando submetido ao teste de modulação da atividade antibiótica. Houve interferência na ação antibacteriana dos aminoglicosídeos, mostrando sinergismos em algumas situações e antagonismos em outras. Sugeri-se que novos testes, como ensaios in vivo sejam realizados para melhor a elucidação do real potencial antibacteriano, que poderá resultar em produtos de baixo custo e fácil acesso para a comunidade. Esforços para isolar os compostos responsáveis por essas atividades estão em andamento.

\section{REFERÊNCIAS}

BRASILEIRO, B. G.; PIZZIOLO, V. R.; RASLAN, D. S.; JAMAL, C. M.; SILVEIRA, D. Antimicrobial and cytotoxic activities screening of some Brazilian medicinal plants used in Governador Valadares district. Rev. Bras. Cienc. Farm., v. 42, p. 195-202, 2006.

CANTON, M.; ONOFRE, S. B. Interferência de extratos da Baccharis dracunculifolia DC., Asteraceae, sobre a atividade de antibióticos usados na clínica. Rev. Bras. Farmacog., v. 20, p. 348-354, 2010.

CLSI - Clinical and Laboratory Standards Institute. Methods for dilution antimicrobial susceptibility tests for bacteria that grow aerobically. $5^{\text {a }}$ ed. Villanova, PA: CLSI approvedstandard.M7-A5, v. 20, 2000.

COUTINHO, H. D. M., COSTA, J. G. M., LIMA, E. O., SIQUEIRA-JR, J. P. Additive effects of Hyptis martiusii Benth with aminoglycosides against Escherichia coli. Indian J. Med. Res., v. 131, p. 106-108, 2010.

COUTINHO, H. D. M.; COSTA, J. G. M.; SIQUEIRA, J. J. P.; LIMA, E. O. In vitro anti-staphylococcal activity of Hyptis martiusii Benth against methicillin-resistant Staphylococcus aureus-MRSA strains. Rev. Bras. Farmacogn., v. 18, p. 670-6755, 2008.

DI STASI, L. C. 2007. Plantas medicinais verdades e mentiras: o que os usuários e os profissionais de saúde precisam saber. São Paulo: Ed. UNESP, 2007.

FIGUEREDO, F. G.; LUCENA, B. F. F.; TINTINO, S. R.; MATIAS, E. F. F.; LEITE, N. F.; ANDRADE, J. C.; NOGUEIRA, L. F. B.; MORAIS, E. C.; COSTA, J. G. M.; COUTINHO, H. D.; RODRIGUES, F. F. G. Chemica composition and evaluation of modulatory of the antibiotic activity from extract and essential oil of Myracrodruon urundeuva. Pharm. Biol., v. 52, p. 560-565, 2014. 
FRANCISCO, K, S, F. 2010. Fitoterapy: on option in odontological treatment. Rev. Saúde, v. 36, p. 18-24, 2010.

GALES, A. C.; REIS, A. O.; JONES, R. N. Contemporary assessment of antimicrobial susceptibility testing methods for polymixyn B and colistin: review of available interpretative criteria and quality control guidelines. J. Clin. Microbiol., v. 39, p. 183190, 2001.

GUEDES, R. S.; ALVES, E. U.; BRUNO, R. L. A.; GONÇALVES, E. P.; COSTA, E. G.; MEDEIROS, M. S. Armazenamento de sementes de Myracrodruon urundeuva Fr. All. em diferentes embalagens e ambientes. Rev. Bras. Plantas Med., v. 14, p. 68$75,2012$.

HELANDER, I. M., ALAKOM, I. H. L., LATVA, K. K., MATTILA, S. T., POL, I., SMID, E. J., GORRIS, L. G. M.; VON, W. A. Characterization of the Action of Selected Essential Oil Components on Gram-Negative Bacteria. J. Agric. Food Chem., v. 46, p. 3590-3595, 1998.

JAVADPOUR, M. M.; JUBAN, M. M.; LO, W. J.; BISHOP, S. M.; ALBERTY, J. B.; COWELL, S. M.; BECKER, C. L.; MCLAUGHLIN, M .L. De novo antimicrobial peptides with low mammalian cell toxicity. J. Med. Chem., v. 39, p. 3107-3113, 1996.

KAZMIRCZAK, A.; GIOVELLI, F. H.; GOULART, L. S. Caracterização das infecções do trato Urinário Diagnosticadas no Município de Guarani das Missões - RS. Rev. Bras. Anal. Clin., v. 37, p. 205-207, 2005.

LORENZI, H.; MATOS, F. J. A. Plantas medicinais no Brasil - nativas e exóticas. Nova Odessa. São Paulo: Instituto Plantarum, 2002.

MATIAS, E. E. F.; COUTINHO, H. D.; COSTA, J. G. Avaliação da atividade antibacteriana e moduladora da resistência bacteriana à aminoglicosídeos de extratos polares e apolares de Croton campestris A. (velame), OcimumgratissimumL. (alfavaca) e Cordia verbanacea DC. (erva-baleeira). Dissertação (Programa de PósGraduação em Bioprospecção Molecular) - Universidade Regional do Cariri, 2010.

OLIVEIRA, J. F. P.; CIPUllO, J. P.; BURDMANN, E. A. Nefrotoxicidade dos aminoglicosídeos. Braz. J. Cardiovasc. Surg., v. 21, p. 444-452, 2006.

PINHO, L.; SOUZA, P. N. S.; SOBRINHO, E. M.; ALMEIDA, A. C.; MARTINS, E. R. Atividade antimicrobiana de extratos hidroalcoolico das folhas de alecrim- pimenta, aroeira, barbatimão, erva baleeira e do farelo da casca de pequi. Cienc Rural, v. 42, p. 326-331, 2012.

SILVA, W. P.; GANDRA, E. À. Estafilococos coagulase positiva: patógenos de importância em alimentos. Rev. Higiene Alimentar, v. 18, p. 32-40, 2004.

VEIGA, J. R.; PINTO, A. C. Plantas medicinais: cura segura? Quim Nova, v. 28, p. 519-528,

2005.

WENDAKOON, C.; SAKAGUCHI. M. Inhibition of amino acid de carboxylase activity of Enterobacter aerogenes by active componentsin spices. J. Food Products, 58: 280283, 1995.

\section{AGRADECIMENTOS}

A URCA, UFPE, CNPq e Facepe. 